\title{
sciendo TRUST IN TECHNOLOGY IN CASE OF HUMANOIDS USED FOR THE CARE FOR THE SENIOR PERSONS
}

doi:10.2478/mape-2018-0110

Date of submission of the article to the Editor: 04/2018

Date of acceptance of the article by the Editor: 07/2018
MAPE 2018, volume 1, issue 1, pp. 875-881

\section{Assoc. Prof. Joanna Ejdys}

Bialystok University of Technology, Poland

\begin{abstract}
:
The dynamics of demographic changes manifested in the processes of an ageing population affect Poland. In response to the situation, gerontechnology is emerging as an interdisciplinary field of scientific research in which technology is directed towards the aspirations and opportunities of the older persons. One of the examples of technologies that will be able to support the ageing population in the future are humanoids, that is, robots resembling a human being and equipped with artificial intelligence. The purpose of this article was to examine relationships between trust in the use of humanoids to care for the older people, the usefulness of technology, the ease of use, perceived threats, general trust and trust in science and technology. A survey method was used to collect data for research. The electronic questionnaire survey was disseminated among members of the Polish society. 643 filled questionnaires were received.
\end{abstract}

Keywords: technology trust, humanoids, ageing population

\section{INTRODUCTION}

Ageing of the population is one of the more important social issues that will affect the future economic and social development all over the world. According to the United Nations, the number of people globally aged 60 years or more will grow by 56 per cent or from 901 million to 1.4 billion between 2015 and 2030, and by 2050, the global population of older persons is projected to more than double its size of 2015, reaching nearly 2.1 billion (World Population Ageing, 2015). The ageing population has major social and economic consequences, among which most important seem to be:

- growing costs of long-term care;

- the increase of non-communicable diseases and disability;

- growing demand for long-term care services (residential care);

- growing needs to improve the quality and innovativeness of long-term care services;

- increasing requirements for long-term care services;

- a need to improve the productivity of care for the older people in the light of financial problems of the social welfare system (Ejdys, 2015)

The dynamics of demographic change manifested through the ageing population also affects Poland. The share of people over 65 in the general population in Poland will increase from $15.0 \%$ in 2013 to $33 \%$ in 2050 (Population Projection 2014-2050, 2014).

One of the basic challenges facing the social policy focused on the ageing population will be the activation of this group and counteracting dependence. The use of new technologies may also contribute to increasing the independence and activation of older people. In response to the situation with the ageing population, gerontechnology is emerging as a field of science bringing together technology and the ageing process aiming to improve the everyday life of older people (Graafmans et al.,1998). Gerontechnology is an interdisciplinary field of scientific research, in which technology is directed towards the aspirations and opportunities for the older persons (Harrington and Harrington, 2000). 
In the narrow sense, gerontechnology is about communication between the older people and their family members using digital and information technologies that enable the older people to behave independently and improve their mental health through monitoring and maintaining constant contact with the environment (Blaschke, et al., 2009).

From the perspective of the older people, the variety of available and designed technologies that vary in their functionality means that certain technologies are of interest to different groups, such as scientists, technology producers and their final users. One of the examples of technologies that will be able to support the older people in the future are humanoids, i.e. robots that resemble a human being and are equipped with artificial intelligence. Apart from the use of robots in the industry, the number of robotic applications used in everyday life is increasing. According to HSBC reports, only $14 \%$ of respondents would trust a humanoid robot with a surgery, provided it was programmed by leading surgeons, and only $8 \%$ would trust a humanoid robot programmed by experts in relationships (HSBC, 2018). A relatively new area of robot application is processes related to the care for the ageing population.

The scientific literature and popular scientific studies frequently pose the following questions: How could robots help care for the ageing population? Are robots a Solution to declining and ageing populations?

The current and future technologic development depends on two basic factors: the development of technology determined by the level of technological knowledge, and the adaptation and acceptance of technology by society (Nazarko et al., 2017).

One of the important constructs determining the level of acceptance and the use of technology often reflected in models of technology acceptance is trust (Siderska, 2018; HSBC, 2017; Wasiluk, 2016). Technology trust resulting from the perceived properties of technology and environmental factors tends to rely on technology in a situation of potential risk related to its use, determining intentions for the future use of technology (Ejdys, 2017). Lippert pointed out that technology trust expresses the willingness of an individual to be susceptible/influenced by technology, resulting from the expected predictability, credibility and usefulness of technology, and the individual preference for technology (Lippert, 2001).

Technology trust seems to be important in case of conditions of uncertainty, unpredictability of development and the ever-stronger dependence of man on technology (Nazarko, 2017; Halicka, 2017). Trust is also an important factor, which reduces the risks and uncertainties associated with the use of technology.

The issue of technology trust seems to be important in the context of the following characteristics

- predictability of "behaviours" of the technical system (technology), resulting from the assumption of cause-and-effect relations; predictability depends on the knowledge and experience of users and the technical system itself;

- dependability manifested in the desire to be dependent on technical systems, reliance on systems, belief in the reliability of "machines" built on the basis of previously collected evidence confirming the correct functioning of the machine;

- faith, resulting from the lack of certainty that in the future the machine will also be characterised by reliability (Muir, 1987).

In the context of emerging technologies (such as humanoids), the issue of trust in technologies and the factors determining this trust seem to be crucial.

Social research regarding trust in certain technologies is also desired from the cognitive point of view, shaping the public awareness about expected benefits and perceived threats.

The purpose of the article was to examine relationships between five constructs: trust in the use of humanoids for the care of the ageing population ( $\mathrm{TinH})$, the usefulness of technology $(\mathrm{U})$, the ease of use (EoU), perceived threats (PT), general trust (GT) and trust in science and technology (TST). The following hypotheses were verified:

$\mathrm{H} 1$ : The usefulness of technology is positively related to trust in humanoids. 
$\mathrm{H} 2$ : The ease of use is positively related to trust in humanoids.

H3: Perceived threats are negatively related to trust in humanoids.

$\mathrm{H} 4$ : General trust is positively related to trust in humanoids.

H5: Trust in science and technology is positively related to trust in humanoids.

Also, the empirical verification concerned a hypothesis indicating the relationship between the declared trust in humanoids with age and gender of respondents, which allowed to formulate following additional hypotheses.

H6: The level of trust in humanoids is the same across all age groups.

$\mathrm{H} 7$ : The level of trust in humanoids is the same across all gender groups.

\section{METHODOLOGY}

\subsection{Data}

A survey method was used to collect research data. An electronic questionnaire was used to conduct confidential interviews. It was distributed between April and May 2018. The electronic questionnaire survey targeted the Polish society. The number of returned questionnaires amounted to 643 . Of the 643 respondents, $373(58.0 \%)$ were women and $270(42.0 \%)$ were men. The proportion of respondents aged $18-25$ was $32,7 \%$ ( 210 persons), followed by $25.8 \%$ (166 persons) aged 41-60, and 24.9\% (160 persons) aged 26-40 and 16.4\% (107 persons) of persons over 60 .

\subsection{Measures}

Since the construct of technology trust, usefulness, ease to use, perceived threats, trust in science and general trust cannot be directly observed, a series of measures were used for each construct.

All constructs were measured using a seven-point Likert scale to access the degree to which the respondent agreed or disagreed with each of the items (1=totally disagree to 7 =totally agree). The constructs' Cronbach's alpha coefficients were employed (ranging from 0.763 to 0.908). The author used the average score of measures of each construct for further analysis. Constructs and items are presented in Table 1.

Table 1

Constructs and items

\begin{tabular}{|c|c|c|c|c|}
\hline Constructs & Ident. & Items & Mean & $\begin{array}{l}\text { Cronbach's } \\
\text { alpha }\end{array}$ \\
\hline \multirow{3}{*}{$\begin{array}{l}\text { Trust in } \\
\text { humanoids } \\
\text { (TinH) }\end{array}$} & TinH1 & I would be able to trust the robot & 4.33 & \multirow{3}{*}{0.898} \\
\hline & $\mathrm{TinH} 2$ & In the presence of a robot, I would feel safe & 4.21 & \\
\hline & TinH3 & $\begin{array}{l}\text { Living in an old age in the company of a robot could be } \\
\text { nice and pleasant }\end{array}$ & 3.87 & \\
\hline \multirow{5}{*}{$\begin{array}{l}\text { Usefulness of } \\
\text { technology } \\
\text { (U) }\end{array}$} & U1 & $\begin{array}{l}\text { The use of robots will improve the quality of care } \\
\text { services for the older people }\end{array}$ & 4.79 & \multirow{5}{*}{0.908} \\
\hline & U2 & $\begin{array}{l}\text { The use of robots to care for the older people will } \\
\text { improve the safety of older people }\end{array}$ & 4.67 & \\
\hline & U3 & $\begin{array}{l}\text { The use of robots will be of particular importance in the } \\
\text { care of lonely people }\end{array}$ & 5.08 & \\
\hline & U4 & $\begin{array}{l}\text { The use of robots to care for the older people will } \\
\text { contribute to spending the time of the older people in a } \\
\text { pleasant way }\end{array}$ & 3.94 & \\
\hline & U5 & $\begin{array}{l}\text { I believe that being in the presence of a robot can be } \\
\text { pleasant }\end{array}$ & 3.84 & \\
\hline \multirow{2}{*}{$\begin{array}{l}\text { Ease of use } \\
\quad(\text { EoU })\end{array}$} & EoU1 & Robot support should be easy and intuitive & 6.40 & \multirow[b]{2}{*}{0.763} \\
\hline & EoU2 & $\begin{array}{l}\text { I believe that I could learn how to use a robot if I needed } \\
\text { it }\end{array}$ & 6.21 & \\
\hline $\begin{array}{l}\text { Perceived } \\
\text { threats (PT) }\end{array}$ & PT1 & $\begin{array}{l}\text { The use of a robot to care for the older people can be a } \\
\text { source of threats resulting from the unexpected, } \\
\text { unpredictable behaviour of the robot }\end{array}$ & 4.89 & 0.811 \\
\hline
\end{tabular}




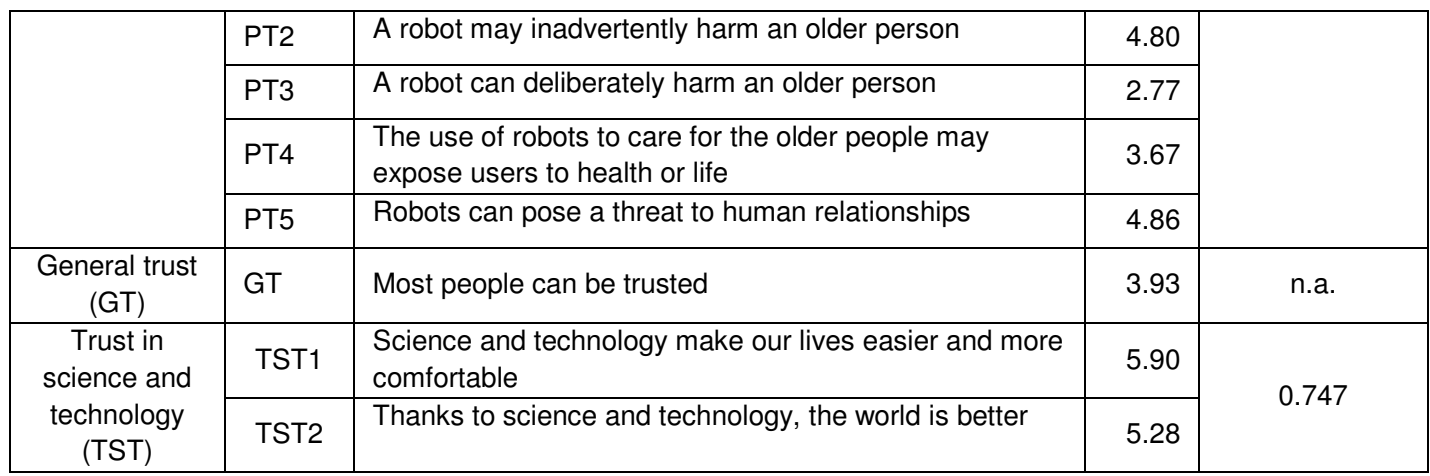

\section{RESULTS}

To reach the scientific goal and verify the hypotheses, the correlation analysis was used. Table 2 shows the correlation matrix for variables. Significant correlations were found between all constructs, influencing trust in humanoids. Trust in humanoids is strongly positively correlated with the usefulness (high correlation). In case of trust in science and technology and perceived threats, the correlation is moderate and weak in the case of the ease of use and general trust. Trust in humanoid is significant but negatively correlated with perceived threats.

Table 2

Correlation matrix (Spearman's coefficient)

\begin{tabular}{|l|r|r|r|r|r|r|}
\hline & Usefulness & \multicolumn{1}{|c|}{$\begin{array}{c}\text { Ease } \\
\text { of use }\end{array}$} & $\begin{array}{c}\text { General } \\
\text { trust }\end{array}$ & $\begin{array}{c}\text { Trust in science } \\
\text { and technology }\end{array}$ & $\begin{array}{c}\text { Perceived } \\
\text { threats }\end{array}$ & $\begin{array}{c}\text { Trust in } \\
\text { humanoid }\end{array}$ \\
\hline Usefulness & 1 & & & & & \\
\hline Ease of use & $0.390^{* *}$ & 1 & & & & \\
\hline General trust & $0.181^{* *}$ & -0.008 & 1 & & & \\
\hline $\begin{array}{l}\text { Trust in science and } \\
\text { technology }\end{array}$ & $0.461^{* *}$ & $0.368^{* *}$ & $0.221^{* *}$ & & \\
\hline Perceived threats & $-0.424^{* *}$ & $-0.126^{* *}$ & -0.005 & $-0.165^{* *}$ & & 1 \\
\hline Trust in humanoid & $0.813^{* *}$ & $0.314^{* *}$ & $0.290^{* *}$ & $0.462^{* *}$ & $-0.450^{* *}$ & \\
\hline
\end{tabular}

** Correlation is significant at the 0.01 level (2-tailed).

The correlation analysis allowed the positive verification of all hypotheses $(\mathrm{H} 1, \mathrm{H} 2, \mathrm{H} 3, \mathrm{H} 4$, $\mathrm{H} 5)$. To verify the hypothesis H6, non-parametric ANOVA Kruskal-Walls test was used, and to verify the hypothesis $\mathrm{H} 7$, the Mann-Whitney test was used. The statistical verification allowed to reject both hypotheses. The research proved that the level of trust in humanoids is differentiated across age groups (the significance level of .0.009), as well as gender groups (the significance level of .0.01). For the purposes of graphical presentation of the level of trust in humanoids among four age groups and gender group, box plots were used (Figs 1-2).

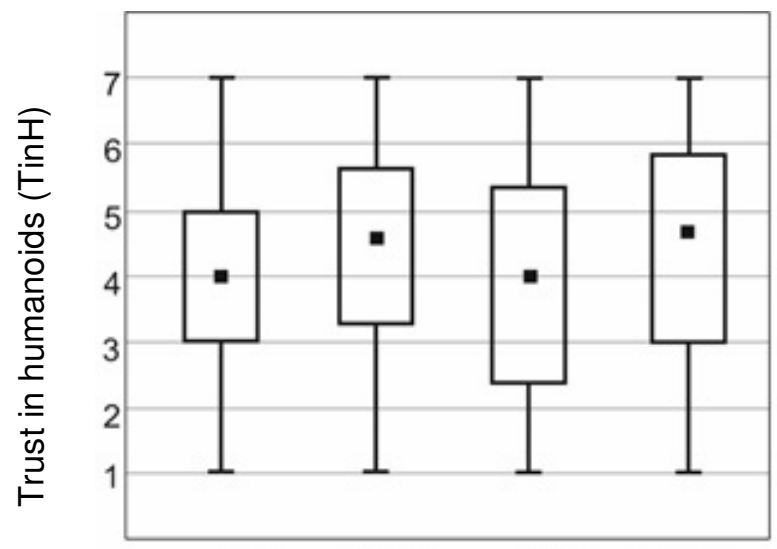

age 18-25 age 26-40 age 41-60 over 60

Fig. 1. Trust in humanoids in four age groups 


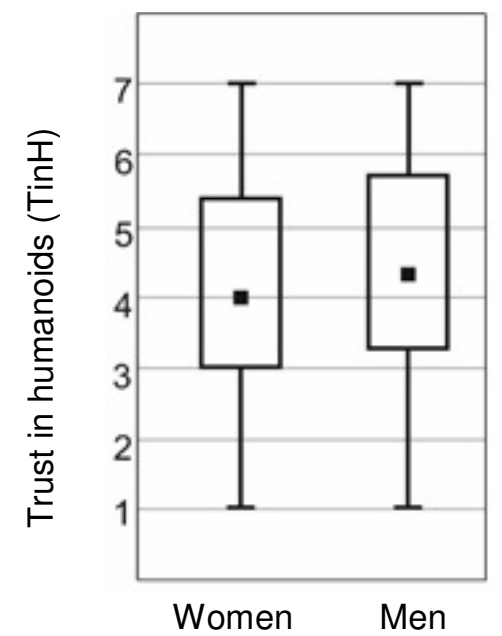

Fig. 2. Trust in humanoids in gender groups

\section{DISCUSSION}

The conducted research indicated that from the perspective of building social trust in new technology (e.g. humanoids), the usefulness of new solutions is an important factor. The study positively verified the hypothesis indicating that the usefulness of technology is positively related to trust in humanoids. While assessing the individual usefulness of the humanoid technology, the respondents rated highly the fact that robots will be particularly important in the care of lonely people (the mean of 5.08), improvement of the quality of care services for the ageing population (the mean of 4.79) and the improvement of the safety of older people (the mean of 7.67).

Correlation analysis also showed that relationships between perceived threats $(\mathrm{H} 3)$, trust in science and technology $(\mathrm{H} 5)$, general trust $(\mathrm{H} 4)$ and trust in humanoids are statistically significant $(p<0.001)$. In relation to threats, respondents were afraid that a robot could be a source of threats resulting from the unexpected, unpredictable behaviour of the robot (the mean of 4.89), that a robot might inadvertently harm an elderly (the mean of 4.80 ) and that robots could pose a threat to human relationships (the mean of 4.86). Trust in humanoids is strongly negatively correlated with threats perceived by respondents.

Previous studies (Lippert, Swiercz, 2005), as well as the author's findings, confirm that general trust indicates trust in a particular technology. Belanger and Carter proved that general trust positively influenced trust in the technology such as the Internet (Belanger, Carter, 2008). The author's studies confirmed that general trust positively influenced the trust in robots. General trust was measured using the measure "Most people can be trusted" formulated under the World Values Survey by the Institute for Comparative Survey Research (World Values Survey, 2018).

In the context of results conducted by the Institute for Comparative Survey Research, Poland belongs to the group of countries characterised by a relatively low level of general trust. Only every fifth citizen was convinced that other people could be trusted (World Values Survey, 2018). Therefore, building trust in technology will be a long-time process requiring changes in the general level of trust of Poles, as well as trust in science and technology.

Another factor determining the trust in technology is the ease of its use. In their research, Pavlou and Gefen (2004) analysed the impact of variable ease of use and technology trust and showed that the ease of use of newly implemented technology positively influences the level of technology trust during its use (Pavlou, Gefen, 2004). Similar results were obtained by Klein (2007) dealing with online communication systems between a doctor and a patient (Klein, 2007). Also, the author's research confirmed that the ease of use determines the trust in humanoids. When assessing the ease of use of technology, respondents indicated that robot 
support should be easy and intuitive (the mean of 6.40). Respondents also believed that they could learn how to use a robot if they needed it (the mean of 6.21).

The obtained results confirmed that the level of trust in robots is varied depending on the age and sex of the respondents. Men were more likely to trust humanoids used in the care of the ageing population than women.

Considering the diversity of respondents by their age, people whose trust in humanoids was at the highest degree were people aged 26-40 and people over 60. The trust in humanoids of the youngest, aged 18-25, was the least. It is astonishing that trust generally increases with age. This may be the result of citizens' awareness of the consequences of demographic changes and perceived problems in the future. Older people, considering the involvement of their children in professional work and family life, see the possible problems associated with self-care. And, therefore, they are more willing to entrust humanoids with the care for the ageing population.

\section{CONCLUSION}

The conducted research among the first in the country. Its main goal was to get to know the opinion of the Poles about trust in using humanoids to care for the ageing population. An indirect research goal was to raise the level of public awareness in the field of new technology development. Considering the interdisciplinary nature of the research related to the implementation and dissemination of emerging technologies, the issue of technology trust, in addition to technological and economic factors, seems to be interesting and requires further research. The directions of future research should concern the construction of theoretical models of factors determining technology trust. In the author's opinion, in relation to each technology, considering its specificity, separate models of technology trust should be built. The empirical model verification can be a source of scientific and practical knowledge used in the process of improving technology acceptance models (Technology Acceptance Model -TAM), also in the context of responsible research and innovation paradigm (Nazarko, 2016).

\section{ACKNOWLEDGEMENTS}

The research was conducted within S/WZ/1/2017 project and financed from the funds of the Ministry of Science and Higher Education.

\section{REFERENCES}

Beard, J.R., S. Biggs, D. E. Bloom, L.P. Fried, P. Hogan, A. Kalache, S. Jay Olshansky (2011). Global Population Ageing: Peril or Promise? Geneva: World Economic Forum.

Belanger, F. And Carter, L. (2008). Trust and risk in e-government adoption. Journal of Strategic Information Systems, 17(2), pp. 165-176.

Blaschke, Ch. M., Freddolino, P.P. and Mullen, E. E. (2009). Ageing and technology: a review of the research literature. The British Journal of Social Work, 39(4), pp. 641-656.

Demographic Surveys and Labour Market Department (2014). Population Projection 2014-2050, Warsaw: CSO.

Ejdys, J. (2015). Innovativeness of residential care services in Poland in the context of strategic orientation. Procedia - Social and Behavioral Sciences, 213, pp. 746-752.

Graafmans, J., Taipale, V. And Charness, N. (1998). Gerontechnology: a sustainable investment in our future. Amsterdam, IOS Press.

Halicka, K. (2017). Main Concepts of Technology Analysis in the Light of the Literature on the Subject. Procedia Engineering, 182, pp. 291-298

Harrington, T.L., Harrington M.K. (2000). Gerontechnology. Why and How, Eidhoven: Herman Bauman Foundation for Gerontechnology

HSBC (2017). Trust in Technology.

Klein, R. (2007). Internet based patient physician electronic communication applications: patient acceptance and trust. E-Service Journal, 5(2), pp. 27-51.

Lippert, S. K., and Swiercz, M. P. (2005). Human resource information systems (HRIS) and technology trust. Journal of Information Science, 31(5), pp. 340-353.

Lippert, S.K. (2001). An Exploratory Study Into The Relevance of Trust in the Context of Information Systems Technology. Doctoral Dissertation, Washington: The George Washington University. 
Magruk, A. (2017). Concept of uncertainty in relation to the foresight research. Engineering Management in Production and Services, 9(1), pp. 46-55.

Muir, B.M. (1987). Trust between humans and machines, and the design of decision aids. International Journal Man-Machine Studies, 27(5-6), pp. 527-539.

Nazarko, J., Ejdys, J., Halicka, K., Magruk, M., Nazarko, Ł., Skorek, A. (2017). Factor Analysis as a Tool Supporting STEEPVL Approach to the Identification of Driving Forces of Technological Innovation. Procedia Engineering, 182, pp. 491-496.

Nazarko, Ł. (2016). Responsible Research and Innovation - A New Paradigm of Technology Management, 9th International Scientific Conference "Business and Management 2016", 12-13 May 2016, Vilnius, Lithuania.

Nazarko, Ł. (2017), Future-Oriented Technology Assessment, Procedia Engineering, 182, pp. 504-509.

Pavlou, P.A., Gefen, D. (2004). Building effective online marketplaces with institution-based trust. Information Systems Research, 15 (1), pp. 37-59.

Radziszewski, P., Nazarko, J., Vilutiene, T., Dębkowska, K., Ejdys, J., Gudanowska, A., Halicka, K., Kilon, J., Kononiuk, A., Kowalski, K. J., Król, J B., Nazarko, Ł., Sarnowski, M. (2016). Future trends in road pavement technologies development in the context of environmental protection. The Baltic Journal of Road and Bridge Engineering, 11(2), pp. 160-168.

Siderska, J. (2018). Cloud manufacturing: a service-oriented manufacturing paradigm. A review paper. Engineering Management in Production and Services, 10(1), pp. 22-32.

United Nations, Department of Economic and Social Affairs, Population Division (2015). World Population Ageing 2015 (ST/ESA/SER.A/390).

Wasiluk, A. (2016). Trust and areas of cooperation between companies and institutions of science. Conference: 21st International Scientific Conference on Smart and Efficient Economy Preparation for the Future Innovative Economy Brno: Brno University of Technology, pp. 629636.

World Values Survey. Available at: http://www.worldvaluessurvey.org/wvs.jsp [Accessed 8 May 2018]. 